\title{
Using nerve transfer to restore prehension and grasp 12 years following spinal cord injury: a case report
}

\author{
Ida K. Fox ${ }^{1} \cdot$ Christine B. Novak ${ }^{2} \cdot$ Lorna C. Kahn $^{3} \cdot$ Susan E. Mackinnon ${ }^{1} \cdot$ Rimma Ruvinskaya $^{4} \cdot$ Neringa Juknis $^{4}$
}

Received: 27 December 2017 / Revised: 14 February 2018 / Accepted: 19 February 2018

(c) International Spinal Cord Society 2018

\begin{abstract}
Introduction Nerve transfers are used routinely for reconstruction of hand function following lower motor neuron lesions. In people with cervical spinal cord injury (SCI), this novel and alternate reconstruction option may be useful to restore prehension and grasp, and improve hand function.

Case presentation A 34-year-old male presented 12 years post-mid-cervical SCI. Pre-operative electrodiagnostic studies revealed intact lower motor neurons below the SCI level. He elected to undergo nerve transfer surgery to restore hand function. Intraoperative evaluation led to the transfer of a brachialis nerve to several median nerve recipient branches. Post surgery, he was discharged home and resumed activities of daily living. He achieved independent thumb and finger flexion function and continued to exhibit functional improvement at 4 years post surgery.

Discussion These results should prompt referral for consideration of nerve transfer surgery-an exciting alternative to tendon transfer and neuroprostheses.
\end{abstract}

\section{Introduction}

Hand function is essential to basic activities of daily living (ADLs), and critically influences the level of independence following cervical spinal cord injury (SCI). In people living with SCI, hand function (for independent feeding, etc.) is rated as more important than other activities such as walking and sexual performance [1]. The traditional approach to surgical reconstruction of hand function in SCI uses tendon transfer, tenodesis, and/or functional electrical stimulation to restore critical movements based on the existing function. Although favorable outcomes have been reported with tendon transfers, these surgeries require many weeks of

Ida K. Fox

foxi@wudosis.wustl.edu

1 Division of Plastic \& Reconstructive Surgery, Washington University School of Medicine, St. Louis, MO, USA

2 Division of Plastic \& Reconstructive Surgery, University of Toronto, Toronto, ON, Canada

3 Milliken Hand Rehabilitation Center, Washington University School of Medicine, St. Louis, MO, USA

4 Department of Neurology, Washington University School of Medicine, St. Louis, MO, USA immobilization and non-weightbearing activity, and adaptation and use of these traditional treatments are limited [2].

Nerve transfer surgery is a novel and alternate approach for reconstruction of hand function in people with cervical SCI. In peripheral nerve and brachial plexus injury, nerve transfers are well established, safe and often are the reconstructive method of choice. A nerve transfer coapts an expendable donor nerve from an innervated muscle to a nonfunctional muscle recipient nerve to provide reinnervation and return of critical motor control. Nerve transfers do not have the biomechanical limitations of tendon transfers and a single nerve can be used to reconstruct multiple functions via reinnervation of multiple muscles [3]. Importantly, for patient acceptability, nerve transfers compared to tendon transfers do not require prolonged periods of post surgery immobilization; early range of motion and resumption of baseline activity are encouraged.

There are historic reports describing nerve transfers in SCI $[4,5]$. Many of these reports predate our understanding of the complicated but reproducible internal topography of the peripheral nerve in the upper limb. With the knowledge gained in the last two decades from the experience of nerve transfer in lower motor neuron injuries, nerve transfers have become a compelling surgical option for hand function reconstruction in SCI. 
a

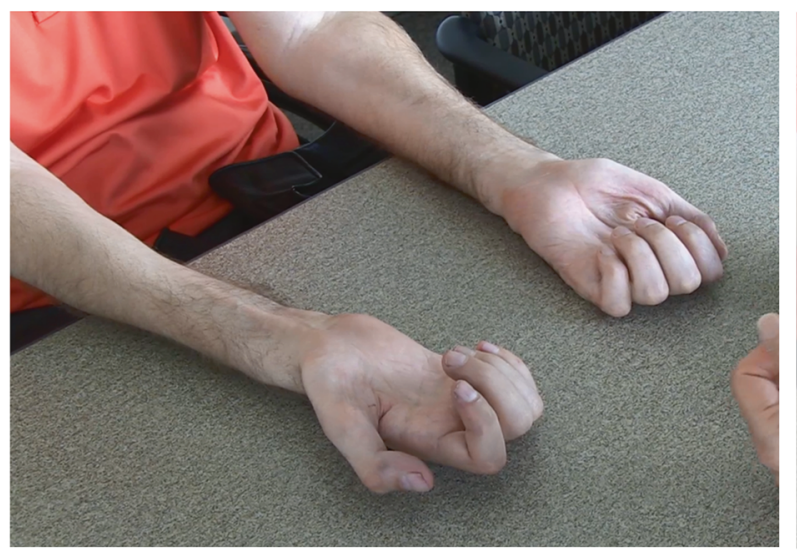

Fig. 1 In this 34-year-old male, who presented 12 years post-mid cervical spinal cord injury, the brachialis branch of the musculocutaneous nerve (function intact) was transferred to branches of the median nerve (function absent due to the intervening cervical spine injury and absence of upper motor neuron control). This peripheral nerve transfer surgery restored thumb and finger flexion independent of the tenodesis b

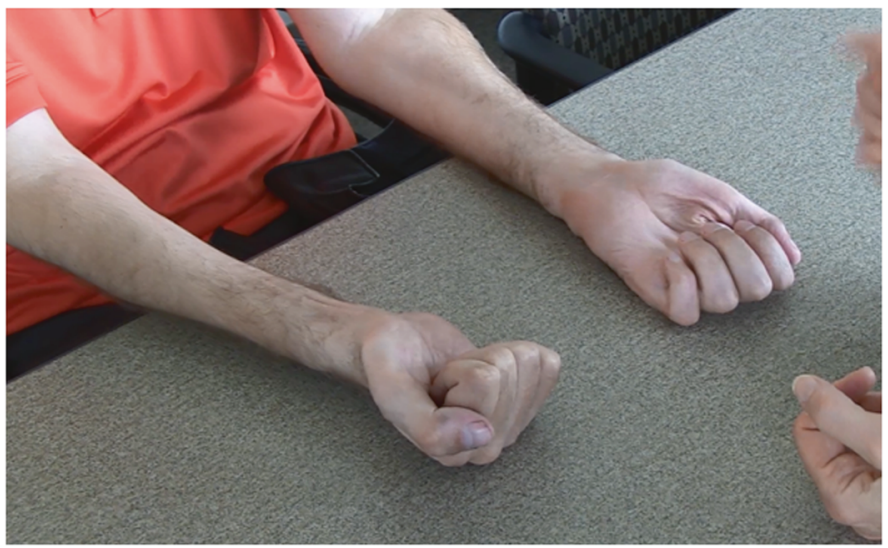

effect. a Both hands in wrist neutral position with resting tone in the fingers. b Both thumb and finger flexion on the right operative side without co-contracture of the brachialis (elbow flexor) donor at 4 years post surgery. (Reproduced with permission. Copyright nervesurgery. wustl.edu, 2016)
Reports suggest that this innovative application of nerve transfers may be promising [6-8] for restoration of digit extension/hand opening [8]. Recently, there have been publications describing restoration of prehension $[6,9,10]$ using the musculocutaneous nerve branch to the brachialis as the donor (the biceps is left intact to provide elbow flexion) and the anterior interosseous nerve (AIN) commonly serves as the recipient. Once the nerve transfer is completed, reinnervation proceeds from the coaptation site in the mid-arm at the rate of an inch a month. With motor re-education therapy, volitional control of the flexor pollicis longus and flexor digitorum profundus (FDP to index and/or long finger) targets are restored.

Nerve transfer in the setting of SCI even years postinjury is physiologically possible. We will present a unique case of long-term follow-up after peripheral nerve transfer surgery to restore both prehension and grasp in a person with cervical SCI presenting over a decade post-injury (Fig. $1)$.

\section{Case presentation}

We certify that all the applicable institutional and governmental regulations concerning ethical use of human volunteers were followed during the course of this research.

\section{Pre-operative findings}

A 34-year-old right hand dominant male presented 12 years after sustaining a cervical SCI from an all-terrain vehicle accident; at that time, he underwent urgent spine decompression and had a prolonged intensive care unit stay with multisystem injuries. His injury was initially described as C5 America Spinal Injury Association (AIS) A and he had subsequent conversion to AIS B.

$\mathrm{He}$ reported right greater than left hand function using tenodesis and had no functional improvements in the previous 7 years. He was independent with self-catheterization using assistive devices and driving; and reported occasional spasticity in the lower extremities and trunk. His goal was to improve the function in his right hand and specifically to gain prehension.

Physical examination revealed normal bilateral shoulder and elbow flexion. On the right side, he had central wrist extension, wrist flexion, and tenodesis-driven hand movement. On the left side, he had radial wrist extension, no wrist flexion and tenodesis-driven hand movement. The joints were supple and no upper limb spasticity was noted; reasonable muscle bulk was preserved throughout. Physical findings are presented in Table 1.

Pre-operative electrodiagnostic evaluation did not identify a superimposed lower motor neuron injury at the C8-T1 level (Table 2). Neuromuscular ultrasonography was performed and showed reduced muscle thickness in some of the musculature with the most profound changes in the left triceps (increased echogenicity). The flexor pollicis longus and pronator quadratus muscles bilaterally did not show findings of severe fibrotic deterioration.

On the basis of the physical examination, and electrodiagnostic and ultrasound assessment, he was scheduled for surgery to undergo nerve transfers to restore prehension in the right hand. 
Table 1 Physical exam findings

\begin{tabular}{|c|c|c|c|}
\hline Motion (muscles) & Right side & Left side & Comment \\
\hline & \multicolumn{3}{|l|}{ Shoulder/upper arm } \\
\hline $\begin{array}{l}\text { Shoulder abduction } \\
\text { (deltoid) }\end{array}$ & $5 / 5$ & $5 / 5$ & Symmetric \\
\hline Elbow extension (triceps) & $5 / 5$ & $2 / 5$ & $\begin{array}{l}\text { Asymmetric with right stronger } \\
\text { then left }\end{array}$ \\
\hline Elbow flexion & $5 / 5$ & $5 / 5$ & $\begin{array}{l}\text { Slight asymmetry with left BR } \\
\text { stronger then right }\end{array}$ \\
\hline Biceps & $\begin{array}{l}\text { Biceps and } \\
\text { brachialis present }\end{array}$ & $\begin{array}{l}\text { Biceps and } \\
\text { brachialis present }\end{array}$ & \\
\hline \multicolumn{4}{|l|}{ Brachialis } \\
\hline \multirow[t]{2}{*}{ Brachioradialis (BR) } & $\begin{array}{l}\text { BR present but } \\
\text { moderately weak }\end{array}$ & $\begin{array}{l}\text { BR present and } \\
\text { slightly weak }\end{array}$ & \\
\hline & \multicolumn{3}{|l|}{ Forearm/wrist } \\
\hline Pronation & $5 / 5$ & $5 / 5$ & Symmetric \\
\hline Supination & $5 / 5$ & $5 / 5$ & Symmetric \\
\hline Wrist Extension (WE) & $5 / 5$ & $5-/ 5$ & $\begin{array}{l}\text { Slight asymmetry with right WE } \\
\text { stronger and more central then left }\end{array}$ \\
\hline ECRL & Present & Present & \\
\hline ECRB & Present & Present & \\
\hline ECU & Flicker of motion & Flicker of motion & \\
\hline \multirow[t]{2}{*}{$\begin{array}{l}\text { Wrist Flexion }(W F)(\text { flexor } \\
\text { carpi radialis) }\end{array}$} & $5 / 5$ & Flicker of motion & $\begin{array}{l}\text { Asymmetric with WF present on } \\
\text { right but not left }\end{array}$ \\
\hline & \multicolumn{3}{|l|}{ Hand } \\
\hline Finger Motion & Tenodesis only & Tenodesis only & $\begin{array}{l}\text { Slightly asymmetric with more } \\
\text { effective tenodesis on right due to } \\
\text { more central WE motion }\end{array}$ \\
\hline
\end{tabular}

$B R$ brachioradialis, ECRB extensor carpi radialis brevis, ECRL extensor carpi radialis longus, $E C U$ extensor carpi ulnaris, $W E$ wrist extension

A detailed examination of the bilateral upper extremities showed moderate asymmetry of function but bilateral absent volitional hand function was noted. This table highlights the asymmetry noted and details function from proximal to distal. Finger motion was through the use of tenodesis (passive finger flexion and extension with active wrist extension and flexion, respectively) alone. Medical Research Council manual muscle testing grade is noted (out of 5, where 0-no function, 1-flicker of motion, 2-motion with gravity eliminated, 3-antigravity motion, 4-antigravity motion against some resistance, 5-full range of motion against full resistance) along with a description of the function comparing the left and right sides

\section{Surgical treatment}

An incision was made at the medial aspect of the arm under non-paralytic general anesthesia. The donor musculocutaneous and recipient median nerves were exposed. Using intraoperative nerve stimulation, the donor and recipient nerves demonstrated excellent motor response indicating continuity of the neuromuscular junction both above and below the level of the SCI.

The operative plan was to perform a nerve transfer of the brachialis branch of the musculocutaneous nerve to AIN to restore prehension as previously described [6]. However, the intrafascicular anatomy of the median nerve at the level of the proposed transfer was unique. It was not technically possible to separate the AIN fascicles from the fascicles providing innervation to the flexor digitorum superficialis (FDS). Therefore, both groups of fascicles were included as recipient nerves. The biceps and lateral antebrachial cutaneous branches of the musculocutaneous nerve and the remaining median nerve fascicles (to pronator teres, flexor carpi radialis and the median sensory territory) were left intact. The operative time was $2.5 \mathrm{~h}$. The length of hospitalization was 1 day and there were no perioperative complications.

Post-operative histologic examination of intraoperatively collected nerve tissue was completed using histomorphometric techniques. The donor brachialis nerve contained 2315 nerve fibers and the recipient AIN/FDS nerve fascicle contained 30,533 nerve fibers. Both nerve specimens had normal nerve architecture and appearance.

\section{Post-surgical course}

Post surgery, elbow flexion remained intact and strong (5/5) as assessed by manual muscle testing. Initially he reported that his weightlifting decreased from lifting $16 \mathrm{~kg}$ on a 
Table 2 Electrodiagnostic testing results

\begin{tabular}{llll}
\hline Test done & Right side & Left side & Normal values \\
\hline Median NCS & & & $>4 \mathrm{mV}$ \\
Median CMAP (ABP to wrist segment) & $6.5 \mathrm{mV}$ & $8.0 \mathrm{mV}$ & $>7 \mu \mathrm{V}$ \\
Median SNAP (wrist to digit 3) & $42 \mu \mathrm{V}$ & $58 \mu \mathrm{V}$ & \\
Ulnar NCS & & $0.7 \mathrm{mV}$ & $>6 \mathrm{mV}$ \\
Ulnar CMAP (ADM to wrist segment) & $1.5 \mathrm{mV}$ & $4 \mu \mathrm{V}$ & $>5 \mu \mathrm{V}$ \\
Ulnar SNAP (wrist to digit 5) & $17 \mu \mathrm{V}$ & \\
\hline
\end{tabular}

$A P B$ abductor pollicis brevis, $A D M$ adductor digiti minimi, $C M A P$ compound muscle action potential, EIP extensor indicis proprius, $N C S$ nerve conduction studies, SNAP sensory nerve action potential

The median motor and sensory NCS were normal. These results suggested preserved axons at the C8/T1 median innervated level. The abnormalities seen for the ulnar nerve suggested a superimposed ulnar neuropathy at the elbow. CMAP's and SNAP's are reported as these values provide quantitative information about the number of intact lower motor neurons

pulley system to $9 \mathrm{~kg}$ but gradually returned to preoperative strength. Forearm pronation, wrist flexion (via flexor carpi radialis), and median nerve sensation remained unchanged from his pre-surgical level. Intensive physical therapy was instituted (with approximately monthly visits and a home exercise program of resisted elbow flexion). At 7 months post surgery, the physical therapist noted active finger flexion (about $10-20^{\circ}$ ) with resisted elbow flexion. At 10 months post surgery, he first noted improved use of the right hand to lift heavier items as well as easier selfcatheterization (without assistive clip) and self-feeding. He continued to have gradual improvement in grip and ADLs. At nearly 2 years post surgery, his grip strength on a standard dynamometer was $0.91 \mathrm{~kg}$.

At 4 years post surgery, he was able to use and control the reinnervated thumb and finger flexion without initiation of elbow flexion co-contracture. He describes the following new and/or improved functions: (1) ability to pull out a ticket at a parking garage dispenser; (2) improved cooking on stove picking up pots and lids; and (3) has eliminated the used of all adaptive devices (such as to brush teeth, etc.). Hand opening remains somewhat limited due to effect of tenodesis only extensor function and the enhanced flexor phase strength. He has declined additional surgical intervention for this.

\section{Discussion}

With appropriate patient selection, nerve transfers can successfully restore volitional hand function even more than 10 years following SCI. Use of these types of nerve transfers has the potential to significantly improve ADL independence (such as feeding) and quality of life, while having minimal donor morbidity and limited post-operative immobilization for people with cervical SCI.

Extrapolation of this well-established surgical technique for those with cervical SCI is an effective approach to improve upper extremity function. However, caution must be taken to assess for the presence of intact lower motor neurons below the level of the SCI. Our case presentation individual, while being more than 10 years post-injury, was a good candidate for a number of important reasons: (1) electrodiagnostic testing of the recipient motor units showed continuity (and this was confirmed with intraoperative direct nerve stimulation prior to nerve transection and transfer); (2) joints were supple and without contracture; and (3) he was not interested in tendon transfer surgery due to the required post surgery splinting and immobilization.

Unique aspects of this case include the multiplicity of functions restored via a single donor and the continued improvement even years post surgery. The ratio of donor to recipient nerve fibers to restore meaningful function has been estimated in the literature at 1:5 [11]. The literature also supports the observed phenomenon of gradual and continuing improvement in function over years post surgery [12].

Nerve transfer surgery can improve hand function with little disruption of existing function and allows individuals to return home the day after surgery. Because only nerves from redundant muscle actions are used as donor nerves, individuals may still pursue future SCI curative therapies without concern for detriment or therapeutic overlap related to the nerve transfer. Future studies are warranted to establish appropriate evaluation and suitability criteria for nerve transfer procedures, the degree of recovery expected after nerve transfer particularly with the long follow-up required, and the donor to recipient nerve fiber ratios to provide optimal gains when limited expendable donors are available.

Acknowledgements This work was supported by the Craig H. Neilsen Foundation Spinal Cord Injury Research on the Translation Spectrum (SCIRTS) Grant "Nerve Transfers to Restore Hand Function in Cervical Spinal Cord Injury”, PI: IKF. We acknowledge Carie R. Kennedy, BSN for her assistance in manuscript preparation and submission. 


\section{Compliance with ethical standards}

Conflict of interest The authors declare that they have no conflict of interest.

\section{References}

1. Snoek GJ, IJzerman MJ, Hermens HJ, Maxwell D, BieringSorensen F. Survey of the needs of patients with spinal cord injury: impact and priority for improvement in hand function in tetraplegics. Spinal Cord. 2004;42:526-32.

2. Curtin CM, Gater DR, Chung KC. Upper extremity reconstruction in the tetraplegic population, a national epidemiologic study. J Hand Surg Am. 2005;30:94-9.

3. Ray WZ, Mackinnon SE. Clinical outcomes following median to radial nerve transfers. J Hand Surg Am. 2011;36:201-8.

4. Benassy J. Transposition of the musculo-cutaneous nerve upon the median nerve. Case report. Med Serv J Can. 1966;22:695-7.

5. Kiwerski J. Recovery of simple hand function in tetraplegia patients following transfer of the musculo-cutaneous nerve into the median nerve. Paraplegia. 1982;20:242-7.
6. Mackinnon SE, Yee A, Ray WZ. Nerve transfers for the restoration of hand function after spinal cord injury. J Neurosurg. 2012;117:176-85.

7. Friden J, Gohritz A. Brachialis-to-extensor carpi radialis longus selective nerve transfer to restore wrist extension in tetraplegia: case report. J Hand Surg Am. 2012;37:1606-8.

8. Bertelli JA, Tacca CP, Ghizoni MF, Kechele PR, Santos MA. Transfer of supinator motor branches to the posterior interosseous nerve to reconstruct thumb and finger extension in tetraplegia: case report. J Hand Surg Am. 2010;35:1647-51.

9. Bertelli JA, Ghizoni MF. Nerve transfers for restoration of finger flexion in patients with tetraplegia. $\mathrm{J}$ Neurosurg Spine. 2017;26:55-61.

10. van Zyl N, Hahn JB, Cooper CA, Weymouth MD, Flood SJ, Galea MP. Upper limb reinnervation in C6 tetraplegia using a triple nerve transfer: case report. J Hand Surg Am. 2014;39:1779-83.

11. Gordon T, Yang JF, Ayer K, Stein RB, Tyreman N. Recovery potential of muscle after partial denervation: a comparison between rats and humans. Brain Res Bull. 1993;30:477-82.

12. Wang JP, Rancy SK, Lee SK, Feinberg JH, Wolfe SW. Shoulder and elbow recovery at 2 and 11 years following brachial plexus reconstruction. J Hand Surg Am. 2016;41:173-9. 